\title{
Currículo paralelo em Medicina, experiência clínica e PBL: uma luz no fim do túnel?
}

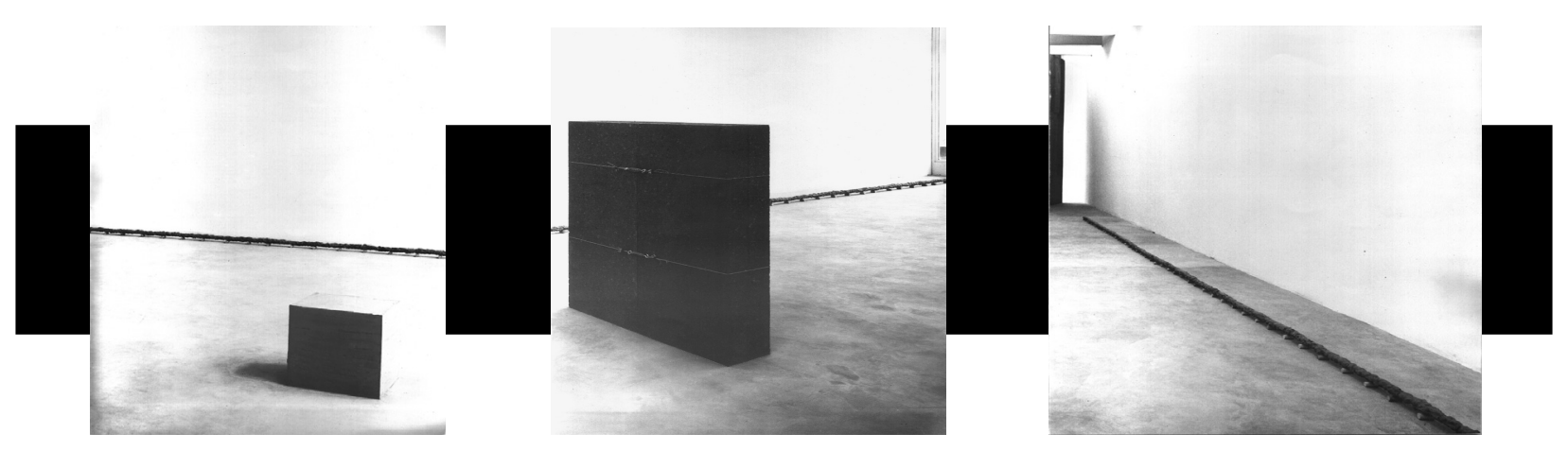

REGO, S. Parallel curriculum in Medicine, clinical practice, and Problem Based Learning: is there a way out? Interface Comunicação, Saúde, Educação, v. 2, n. 3, 1998

This article discusses the parallel curriculum in Medicine, in the light of the theoretical frame of reference of the theory of socialization of adults. It points out the key reasons that lead students to seek for extracurricular apprenticeships, as a means of complementing their formal education. Through the introduction of Problem Based Learning, the author intends to identify the main advantages and obstacles to the implementation of a curriculum based on this pedagogical strategy, and discusses the possibility of this new proposal curtailing the search for extracurricular training programs.

KEYWORDS: medical education, professional education, curriculum.

Este artigo discute o currículo paralelo em Medicina, à luz do referencial teórico da teoria da socialização de adultos. São indicados os principais motivos que levam os estudantes a buscarem os estágios extracurriculares como forma de "complementarem" sua formação. Introduzindo a discussão sobre o Problem-based Learning, o autor busca identificar as principais vantagens e obstáculos na implementação de um currículo baseado nessa estratégia pedagógica e discute as possibilidades dessa nova proposta vir a inibir a busca pelos estágios extracurriculares.

PALAVRAS-CHAVE: ensino médico, formação profissional, currículo.

\footnotetext{
${ }^{1}$ Escola Nacional de Saúde Pública - ENSP, Fundação Oswaldo Cruz - Fiocruz, Rio de Janeiro.

E-mail: rego@ensp.fiocruz.br
} 
${ }^{2}$ A crise no setor

saúde, obviamente, não

se restringe aos

campos aqui

apontados. Não nos estenderemos neste

tema por não ser

relevante para o que aqui abordaremos.

${ }^{3}$ Este artigo tem como referência fundamental minha dissertação de mestrado (Rego, 1994).

${ }^{4}$ Para uma análise das questões relacionadas mais especificamente a América Latina, ver Paiva, Vanilda e Warde Mirian Jorge Dilemas do ensino superior na América Latina. Ed. Papirus, 1994, São Paulo.
O processo de formação dos médicos tem sido objeto de inúmeros conclaves, publicações e debates. Recentemente, temos observado que o debate ultrapassa os limites restritos da própria corporação médica e acadêmica (os meios de comunicação social têm sido pródigos em comentar as deficiências desse processo). A "explosão" democrática na área da saúde teve como seu marco histórico fundamental a $8^{a}$ Conferência Nacional de Saúde. A criação dos Conselhos de Saúde em seus diversos níveis, também tem contribuído para romper as amarras corporativas. A crise, que hoje é uma das mais discutidas características na prestação de serviços de saúde também está presente na formação de seus profissionais e técnicos².

Nesse contexto, temos observado também uma mudança no perfil daqueles que vêm se dedicando ao estudo dos temas afeitos à Educação Médica. Se, no passado, os trabalhos e estudos publicados eram de autoria de eméritos professores de Medicina, vemos, progressivamente, esse perfil de autores se ampliando com a incorporação de estudiosos que têm, na Educação Médica, seu campo de atuação principal. Não são mais apenas médicos os que a ele se dedicam. Temos pedagogos, sociólogos, filósofos, além de outros

profissionais. Com isso, há uma mudança qualitativa nos rumos dos debates em curso, sendo incorporadas diferentes abordagens teóricas $e$ instrumentos de análise. Inegável, também, é constatarmos um possível agravamento na crise que ronda a Escola Médica - inserida na crise enfrentada pela Universidade brasileira -, especialmente apontada ao final dos anos oitenta. Nesse contexto emergiram as propostas de avaliação dos graduados em Medicina, de avaliação das escolas médicas e uma maior difusão de novas alternativas pedagógicas, entre elas o "Problem-Based Learning - PBL".

Neste artigo ${ }^{3}$ pretendemos destacar a importância da "experiência clínica" como valor fundamental na formação dos médicos, algumas das dificuldades encontradas pelas Escolas Médicas em patrocinar a aquisição dessa experiência nas atividades oferecidas em seu currículo e discutir as possibilidades de êxito nesse propósito por meio da incorporação do PBL como metodologia pedagógica.

\section{A crise da Universidade e a crise na Escola Médica}

Devemos entender que a crise na Universidade não é uma exclusividade brasileira, muito menos latino-americana ${ }^{4}$. Santos (1995), tendo como ponto de partida a identificação dos objetivos da Universidade, demonstrou que pouco se modificaram ao longo de sua história, salvo na década de sessenta, quando passaram a ser a investigação, o ensino e a prestação de serviços. A grande novidade nesse momento foi a inclusão da "prestação de serviços", acompanhada de uma série de funções também incorporadas, como, por exemplo, "educação geral pós-secundária; fornecimento de mãode-obra qualificada; educação e treinamento altamente especializados; mobilidade social para os filhos e filhas das famílias operárias; prestação de serviços à região e à comunidade local" (Santos, 1995, p.189). São as contradições entre suas diferentes funções o tema que deve ser abordado prioritariamente para entender-se a Universidade hoje e suas crises, 
identificadas por este autor como: a) de hegemonia - representada pela sua incapacidade de desempenhar algumas de suas funções contraditórias, o que leva os grupos sociais não satisfeitos em sua necessidade (ou o Estado em seu nome) a buscarem meios alternativos para atingi-los. Por exemplo, ao se revelar incapaz de responder às demandas específicas do mercado de trabalho, surgem instituições não universitárias que passam a oferecer formações específicas que atendem a essas necessidades; b) de legitimidade decorrente da incapacidade referida; c) institucional - devido à contradição entre autonomia e produtividade social.

É nesse contexto, e mais especificamente naquilo que Santos chamou de crise de hegemonia, que pretendemos nos deter para introduzir a discussão sobre o currículo paralelo. Antes, porém, é importante que consideremos uma das características dessa crise - a que está relacionada à dicotomia educação e trabalho, que fez com que existissem dois mundos "com pouca ou nenhuma comunicação entre si: o mundo ilustrado e o mundo do trabalho. Quem pertencia ao primeiro estava dispensado do segundo; quem pertencia ao segundo estava excluído do primeiro" (Santos,1995, p.195). Afinal, durante todo o período do capitalismo liberal, a Universidade estava voltada para a produção e transmissão da alta cultura, assim como à socialização de seus alunos para a função de dirigentes da sociedade. Mas, já no final desse período, "a dicotomia passou então a significar a separação temporal de dois mundos intercomunicáveis, a seqüência educaçãotrabalho. A educação cindiu-se entre a cultura geral e a formação profissional e o trabalho entre o qualificado e o não qualificado" (p.196). Essa dicotomia vem sendo questionada em dois níveis: a) sua relação seqüencial pressupõe a existência de uma correspondência estável entre oferta e demanda de trabalho, o que já não ocorre. O tempo de formação universitária de um profissional é bem superior à demanda por este profissional, sendo que o perfil definido para um dado profissional, em um momento específico do mercado, não necessariamente estará mantido após quatro, cinco ou seis anos de formação universitária (acrescida do tempo necessário para a Universidade detectar essa necessidade e redirecionar seus objetivos); b) o questionamento da própria seqüência "educação-trabalho", já que cada vez mais surgem indicativos de busca concomitante de outras formas de educação - vide as exigências da formação permanente $e$ reconversão profissional.

A Escola Médica sofre as repercussões desse fenômeno em todos os seus aspectos. $\mathrm{O}$ planejamento adequado de seu sistema educativo para fazer frente às necessidades previsíveis de mão-de-obra no mercado de trabalho é talvez um de seus exemplos mais eloqüentes. Qual a efetiva atuação da escola médica brasileira no sentido de adequar suas ações educativas, inclusive fomentar a formação deste ou aquele tipo de especialista (ou generalista), tendo como referência a análise concreta das necessidades futuras do mercado de trabalho? Tomando-se um exemplo mais concreto, temos o Programa Saúde da Família, do atual governo federal. Devemos discutir ou não mudanças no planejamento educacional para responder às necessidades demandadas por este programa específico? Será a Universidade capaz ou não de fazê-lo em tempo razoável? Quantas faculdades médicas 


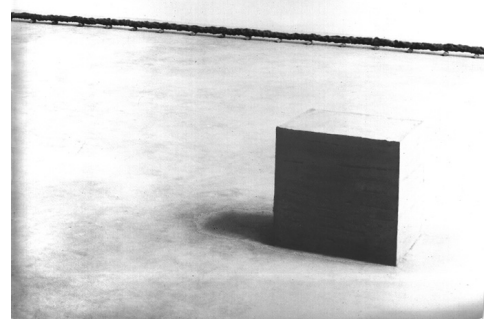

Carlos Fajardo, 1989 têm procurado discutir questões como essa? O fato é que a grande maioria de nossas escolas experimenta a mesma dificuldade de transformação das Universidades em geral. Refletem, em seu seio, a dificuldade de harmonizar os diferentes objetivos que lhes são impingidos, de tal forma que a pesquisa e a prestação de serviços têm, muitas vezes, se sobreposto aos objetivos de ensino (sejam os relacionados à chamada "alta cultura", sejam os de formação profissional).

Sem dúvida, por este caminho poderíamos encontrar explicações razoáveis para o fenômeno do currículo paralelo, não fosse esse, ao menos no caso da Medicina (que tem sido a profissão objeto do maior número de estudos), um fato bem anterior aos anos sessenta. Ou seja, embora esta linha de análise seja muito útil para o entendimento das transformações nos mundos do trabalho e da educação para o destaque de questões decorrentes das contradições entre seus múltiplos objetivos, ela por si só é insuficiente para o entendimento do objeto em questão, embora colabore com a identificação de elementos para a análise.

\section{O currículo paralelo}

Antes de introduzirmos o conceito de "currículo paralelo", devemos nos remeter ao próprio conceito de currículo. Como afirma Koifman (1986), podemos sintetizar as múltiplas conceituações sobre o currículo em dois pólos: currículo como texto de grade curricular e currículo como todo educativo.

No primeiro caso, se aproxima o conceito de currículo ao de 'documento escrito'. Esta analogia está presente não somente em parte da produção escrita, como também no uso coloquial do termo no âmbito educativo: quando os professores, por exemplo, falam de currículo, se referem aos documentos com base nos quais definem seus programas anuais (programa por série a partir da grade curricular).

No segundo caso, está incluído o conceito de currículo oculto, que se refere às experiências vivenciadas no cotidiano escolar, embora não prescritas formalmente em um texto escrito. Para Galli (1989, p. 345) "existem dois tipos de currículo: o formal, manifesto e previsto, que expõe os alunos a determinadas experiências e [prevê] aulas, trabalhos práticos e exames; $e$ o informal ou oculto, que é o conjunto de experiências e estímulos que o estudante recebe sem que tenham sido previstos nem planejados”. Para esta autora, o currículo oculto "consiste na transmissão de uma cultura particular através de processos de identificação e não implica em cursos nem exames. (...). O aluno incorpora a cultura médica, identifica os atributos que obtêm prestígio social e adquire uma escala de valores". Notem que o currículo oculto não se confunde com o chamado "currículo paralelo". Este constitui-se como "o conjunto de atividades extracurriculares que os alunos desenvolvem, subvertendo, na maioria das vezes, a estrutura curricular formal estabelecida pela Faculdade" (Rego, 1994, p.10).

Para que possamos compreender a importância do "currículo paralelo", devemos nos reportar ao conceito de socialização profissional, que teve em 
${ }^{5}$ Embora seja certo que esses valores $e$ atitudes também sejam transmitidos pela inserção do estudante na sociedade em geral, com seus meios de comunicação social tendo um papel destacado. Mas, como dissemos, não se trata de discutir aqui os diferentes aspectos do conceito de socialização ou do currículo oculto.
Merton (1957) e Becker (1984) seus principais estudiosos, inclusive contemplando o caso da profissão médica. Não sendo pertinente estendermo-nos na discussão dessa teoria nesse artigo, recordaremos alguns de seus postulados.

A socialização de adultos, para Merton (1957), inclui mais do que é habitualmente descrito como educação e treinamento: "o mais conspícuo neste processo é a aquisição de um considerável estoque de conhecimento e habilidades o que ocorre mesmo com a menor parcela dos estudantes" (p.41). Além disso, ele afirma ser útil pensar no processo de aquisição da função em duas classes principais: aprendizado direto mediante o ensino didático de um ou outro tipo e aprendizado indireto, no qual atitudes, valores, padrões de comportamento são adquiridos como subprodutos do contato com instrutores e pares, com pacientes e com membros da equipe de saúde. Os estudantes aprendem não somente do padrão ou mesmo do exemplo deliberado; eles também aprendem - e pode ser a forma mais duradoura de aprendizado - do envolvimento contínuo naquela sociedade de staff médico, colegas estudantes e pacientes que constituem a Escola Médica como uma organização social (p.41-2).

Assim, a Escola Médica tradicionalmente é identificada como elemento crucial na aprendizagem profissional "porque representa o contexto institucional no qual se inicia a socialização. A Faculdade de Medicina é importante porque constitui não somente o ambiente onde se transmitem os conhecimentos, experiência, hábitos, atitudes e valores, mas também o meio pelo qual os membros da profissão controlam o que seus colegas serão e o nível de aprendizagem que recebem" (Coe, 1984, p. 234).

Conclui-se, assim, que nesse contexto o estudante de medicina será formado e adquirirá sua base teórica e a "cultura profissional" (entendida em seu sentido amplo, incluindo-se valores e atitudes ${ }^{5}$ ). Mas é nos estágios e na prática regularmente oferecida pela Faculdade que o estudante é efetivamente forjado como profissional. Aí adquire segurança para iniciar-se efetivamente na prática da profissão que escolheu. Em suas atividades práticas ele "desenvolve seu 'eu-profissional', com seus valores característicos, atitudes, conhecimento e habilidades, fundindo-os em disposições mais ou menos consistentes que orientam seu comportamento em uma ampla variedade de situações profissionais ou não" (Merton, 1957, p. 287).

Os estágios extracurriculares (que compõem o chamado currículo paralelo) são uma tradição no ensino da Medicina. Embora nem sempre sua existência seja admitida formalmente pelas Escolas Médicas, pela corporação médica ou autoridades governamentais, eles são não apenas aceitos como até mesmo estimulados ou promovidos. Se em nosso país eles ainda fazem parte do processo de formação de nossos alunos, só encontramos referência a esse tipo de prática na literatura internacional dos países centrais como referências históricas. Referindo-se ao período que antecedeu a Reforma Flexner, Coe assim descreveu o quotidiano nas universidades inglesas $e$ americanas: "os estudantes assistiam a umas poucas lições, com freqüência perseguiam interesses independentes e aprendiam a maior parte de seus conhecimentos acompanhando os médicos em suas visi 
salas do hospital. Os exames versavam em sua maior parte sobre os conhecimentos de ciências básicas e deixavam pouco lugar para a aplicação destas.(...). Os programas eram muito flexíveis e, exceto em alguns casos, era permitido aos estudantes procurarem o seu próprio ensino" (Coe, 1984, p. 234-5). Esta situação, com as ressalvas indispensáveis, uma vez que não vivemos uma situação de anomia $e$ tampouco os exames costumam ser tão desvinculados do campo de atuação prática de um médico, poderia ser referida ao nosso país.

Àqueles mais renitentes em aceitar esta comparação, apresentamos um extrato do Parecer $n^{\circ}$ 506/69, aprovado pelo Conselho Federal de Educação em 11/07/69, que buscava enaltecer as transformações que adviriam da Reforma Universitária e que superariam seu diagnóstico: "nenhum médico dos que se formaram no Brasil até aquela época cumpriu senão parcela reduzidíssima dos horários oficialmente estabelecidos pelas escolas. Era praxe vincular-se cada estudante, desde o segundo ou terceiro ano, a determinado serviço clínico, onde, no horário oficialmente destinado ao aprendizado teórico das várias disciplinas, procurava aprender ou exercitar-se nas tarefas necessárias à prática da profissão, com desconhecimento quase completo do programa escolar" (Santos, 1987, p.229).

Como pode ser facilmente constatado nas Escolas Médicas (ou mesmo em anúncios classificados dos principais jornais do país), os estudantes de Medicina não deixaram de procurar tais estágios, assim como as Escolas Médicas não têm maiores preocupações com a freqüência a eles por seus alunos. E por que isto não ocorre? Várias são as explicações possíveis para esse fato, mas nos deteremos apenas naquelas que nos parecem mais relevantes.

Em primeiro lugar, cada vez mais temos observado que os critérios de aprovação e de acompanhamento do desempenho dos alunos são objeto de menos reflexão pelo conjunto da escola. Como avaliar o desempenho de um aluno? Qual a política de cada instituição a esse respeito? Qual é a política adotada para o controle da freqüência dos alunos nas aulas teóricas, práticas e nas práticas de enfermaria e no internato? Dificilmente encontraremos uma proporção significativa entre as escolas que possuam uma diretriz que oriente seus docentes nesses assuntos. $\mathrm{Na}$

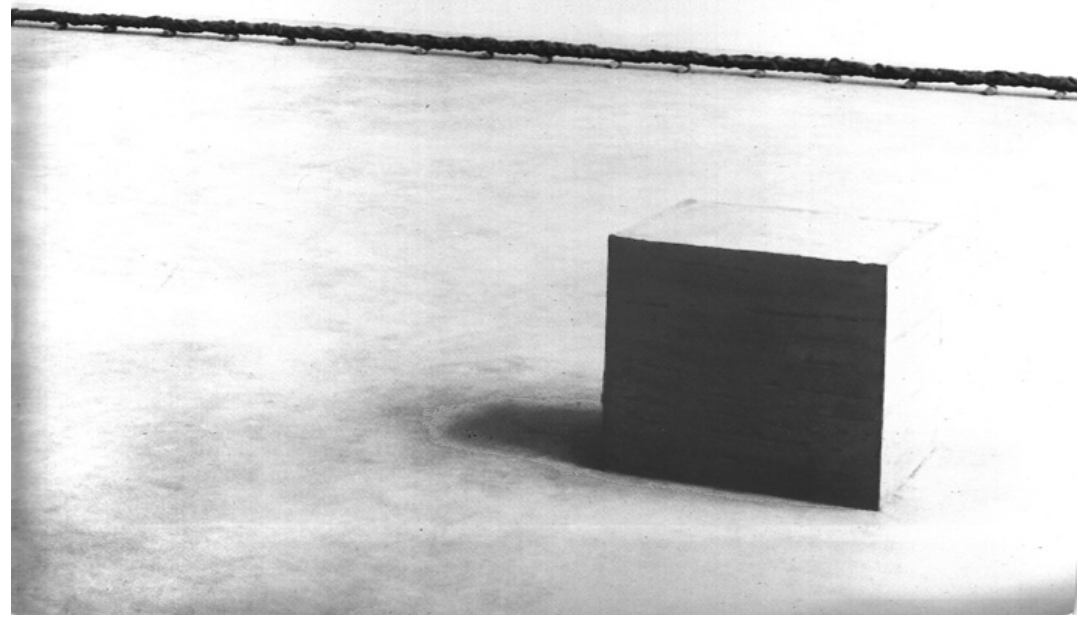
maioria das vezes, são os departamentos (ou ainda os próprios coordenadores de disciplina) que estabelecem seus critérios, quase sempre baseados na tradição ou em experiências pessoais. Não houvesse uma grande flexibilidade no trato dessas questões, seria inviável que todos os alunos entrevistados por nós em um recente estudo a esse respeito, realizado em uma das mais 
tradicionais escolas médicas do país, afirmassem terem feito ao menos um estágio extracurricular durante seu curso (sem que esses estágios fossem necessariamente no período noturno).

Mas esta não é nem a única nem a principal razão para existência desses estágios. O fato é que eles têm sido tolerados, aceitos e incentivados por docentes e pela própria escola médica há muitos e muitos anos. Poderíamos, portanto, supor que justamente esta tradição possa ser o fator de tolerância a essa prática. Afinal, o ensino médico em tempos mais remotos era caracterizado pela relação do mestre diretamente com o aprendiz, em uma relação tutorial intensa. $O$ aprendiz acompanhava o mestre em sua prática $e$ assim ele aprendia. A seqüência educação-trabalho era, como hoje volta a ser posta em discussão, inexistente. Aprendia-se trabalhando, acompanhando seu mestre. Mas para que possamos acatar a hipótese da tradição, seria necessário que a relação tutorial ainda fosse observada, em nossos dias, no cotidiano das práticas extracurriculares, e isso não ocorre. Na maioria dos hospitais onde esses estágios são oferecidos, inexistem programas pedagógicos para os estágios ou mesmo a possibilidade de uma relação tutorial efetiva, ainda que sob a forma de uma simples supervisão. O que se observa é uma supervisão "formal". Um "estar disponível" em caso de dúvidas, ou, às vezes, até uma disponibilidade apenas formal.

Sendo assim, só iremos encontrar uma explicação mais satisfatória tanto para a busca dos alunos pelos estágios extracurriculares como para a tolerância implícita da corporação médica por esse tipo de prática, se algo mais estiver em jogo nesse processo. Esse diferencial é a chamada experiência clínica.

\section{A experiência clínica}

A experiência clínica é um dos valores fundamentais da profissão médica. Decorre diretamente da prática da profissão, prática essa que, para os estudantes, já era referida em 1974 pela então Comissão de Ensino Médico do Ministério da Educação e Cultura - MEC (1974, p.10): "a componente essencial da formação do estudante de Medicina reside nas características do atendimento dos pacientes no ambiente hospitalar, do qual participa na qualidade de estagiário ou de interno". Nesta mesma direção apontava o clássico trabalho de Miller (1961, p.137-45) que preconizava ser o trabalho clínico "incomparável, e por essa razão geralmente considerado como o verdadeiro coração da educação médica”.

A valorização da prática na formação do médico está clara também no trabalho de Merton (1957, p. 41-2) ao afirmar que "deste ponto de vista, os estudantes de Medicina estão engajados em estudar as funções profissionais do médico através da combinação tanto de seu componente de conhecimento, habilidades, atitudes e valores, como em serem motivados e habilitados para desempenhar este papel num estilo social e profissionalmente aceitável".

Esta é, portanto, componente essencial da transformação do estudante em médico. É a busca pela aquisição dessa experiência uma das principais forças que mobilizam os alunos em seu período de formação - eles valorizam a 
experiência clínica (como de resto a corporação médica) e procuram adquirila sempre que possível. Desejam acompanhar e tratar pacientes com doenças que esperam tratar freqüentemente após a formatura. E esperam, ainda, que seu contato com esses pacientes se dê em uma situação semelhante àquela que acreditam experimentarão após a formatura.

Mas afinal, como definir a "experiência clínica"? Para tal, recorreremos a Becker (1984, p. 231).

Este termo refere-se à verdadeira experiência em lidar com pacientes $e$ doenças, e o principal significado desta expressão repousa na polarização implícita com o 'aprendizado de livros'. Experiência clínica, na visão adotada para este termo, confere ao médico um conhecimento que ainda não foi sistematizado e verificado cientificamente. Não é possível adquirir este conhecimento através do estudo acadêmico - é necessário observar o fenômeno clínico e lidar com os problemas clínicos diretamente (grifo nosso). A experiência clínica pode inclusive substituir o conhecimento comprovado cientificamente, pode ser usado para legitimar um conjunto de opções de procedimentos para o tratamento de um paciente e, da mesma forma, pode ser usada para contra-indicar alguns procedimentos que tenham sido estabelecidos cientificamente.

A experiência clínica, portanto, só pode ser adquirida com a prática. Ela está intimamente ligada ao conceito de que a Medicina é uma Arte, antes de ser uma Ciência. E os estudantes de medicina aprendem cedo a valorizar essa experiência, só adquirida com a prática. Eles parecem se guiar por uma pergunta: "Como posso aproveitar melhor meu tempo para preparar-me para a prática profissional como médico?". Foi ainda Becker quem primeiro destacou esta característica e sistematizou suas reflexões sobre este conceito, como se segue:

\footnotetext{
1 É importante para um médico ter experiência clínica.

2 As atividades na faculdade são boas para sua formação quando dão aos estudantes a oportunidade de adquirir experiência clínica ou dão a eles acesso à experiência clínica de seus professores; são ruins quando não fornecem nenhuma dessas coisas.

3 Um estudante está fazendo um progresso real em sua preparação para a prática quando ele pode demonstrar para si próprio e para outros que ele absorveu algumas lições da experiência clínica (...). Nós concluímos, do exame de nossos dados, que os alunos adotam esta perspectiva e organizam seu comportamento por caminhos congruentes com ela (Becker, 1984, p. 242).
}

A introdução do valor "EXPERIÊNCIA CLÍNICA", na análise dos estágios extracurriculares, clareia diversos pontos que até então estavam obscuros em nossa análise, como por exemplo: porque os alunos dizem que os buscam "para complementar sua formação", "para aprender o que a faculdade não ensina", "para aprender a medicina do dia-a-dia", "para aprender a tratar os pacientes de verdade", e outras respostas semelhantes. É exatamente por reconhecerem que esta experiência é passível de ser adquirida nos locais de grande movimento de pacientes, onde eles podem ver não um ou dois casos 
de determinada patologia, mas diversos. Onde eles podem ver o profissional médico em seu "verdadeiro" local de trabalho, longe do viés que o Hospital doenças mais raras e para os casos mais complexos, a despeito das mudanças no perfil observadas em muitos deles. Este viés ainda não foi rompido, apesar dos convênios MEC/Ministério da Previdência e Assistência Social MPAS da década de setenta e da recente implantação do Sistema único de Saúde.

É nessa perspectiva que os estágios extracurriculares são aceitos com tamanha facilidade pela corporação médica. Cada profissional reconhece, na busca dos estudantes, um movimento coerente para o aperfeiçoamento de sua prática, de ampliação de sua própria experiência clínica.

Portanto, algo está faltando nas atividades desenvolvidas pelos estudantes nas Faculdades e que eles estão encontrando, por conta própria, nos serviços de saúde. Este algo mais, traduzido às vezes como "botar a mão na massa" ou "buscar segurança na prática", é a possibilidade de obter a experiência clínica.

Em que a experiência adquirida nos estágios extracurriculares difere daquela obtida no seio das Escolas Médicas?

Comecemos pelas aulas práticas das diversas disciplinas. Nestas, o papel destinado aos estudantes é, via de regra, o de observadores. São aulas demonstrativas, nas quais são exibidos - qual atlas ilustrado e interativo pacientes portadores de patologias específicas. Mesmo nas atividades de enfermaria, a responsabilidade atribuída aos alunos que ainda não estão no período de internato é muito pequena. Nem mesmo a responsabilidade de

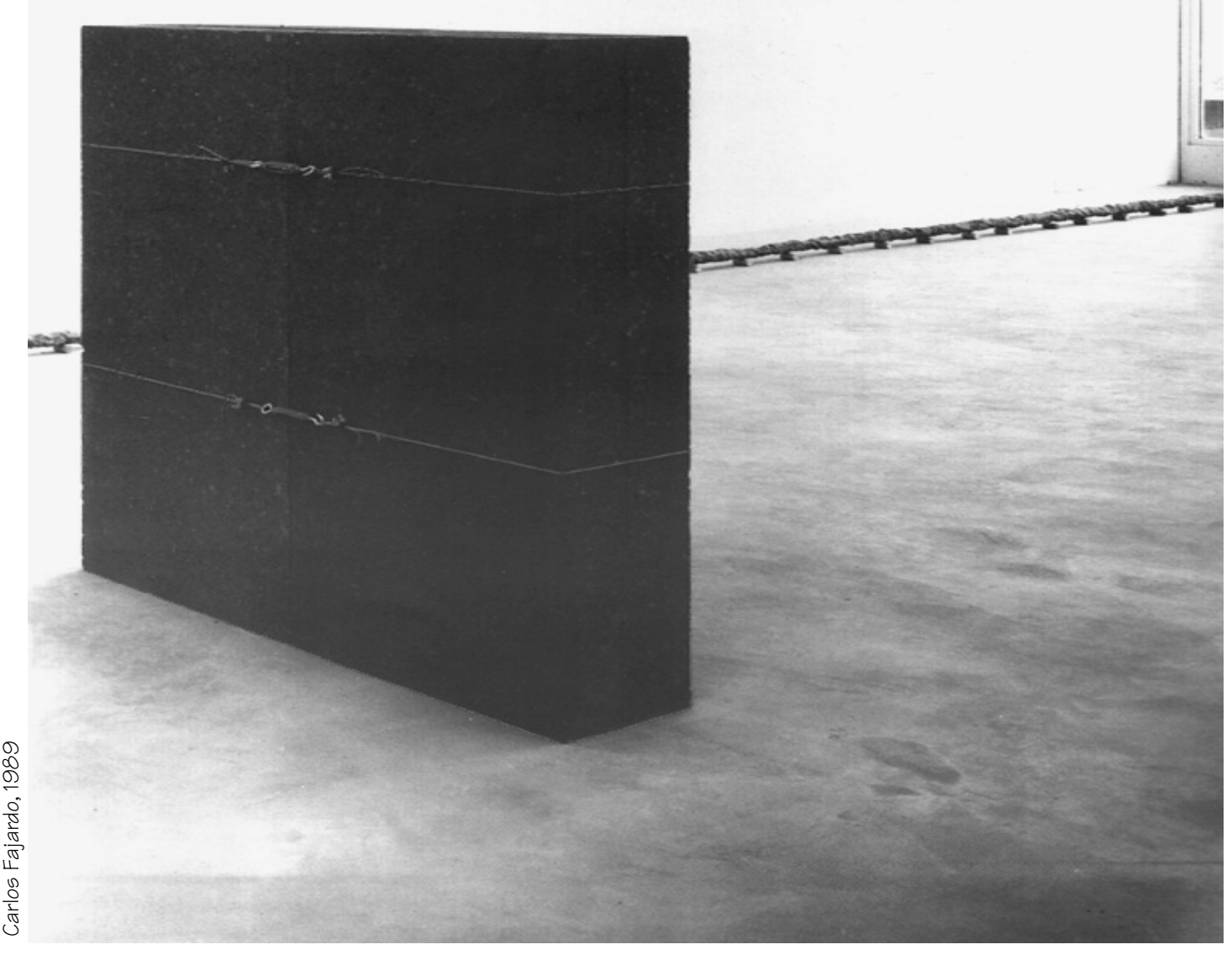




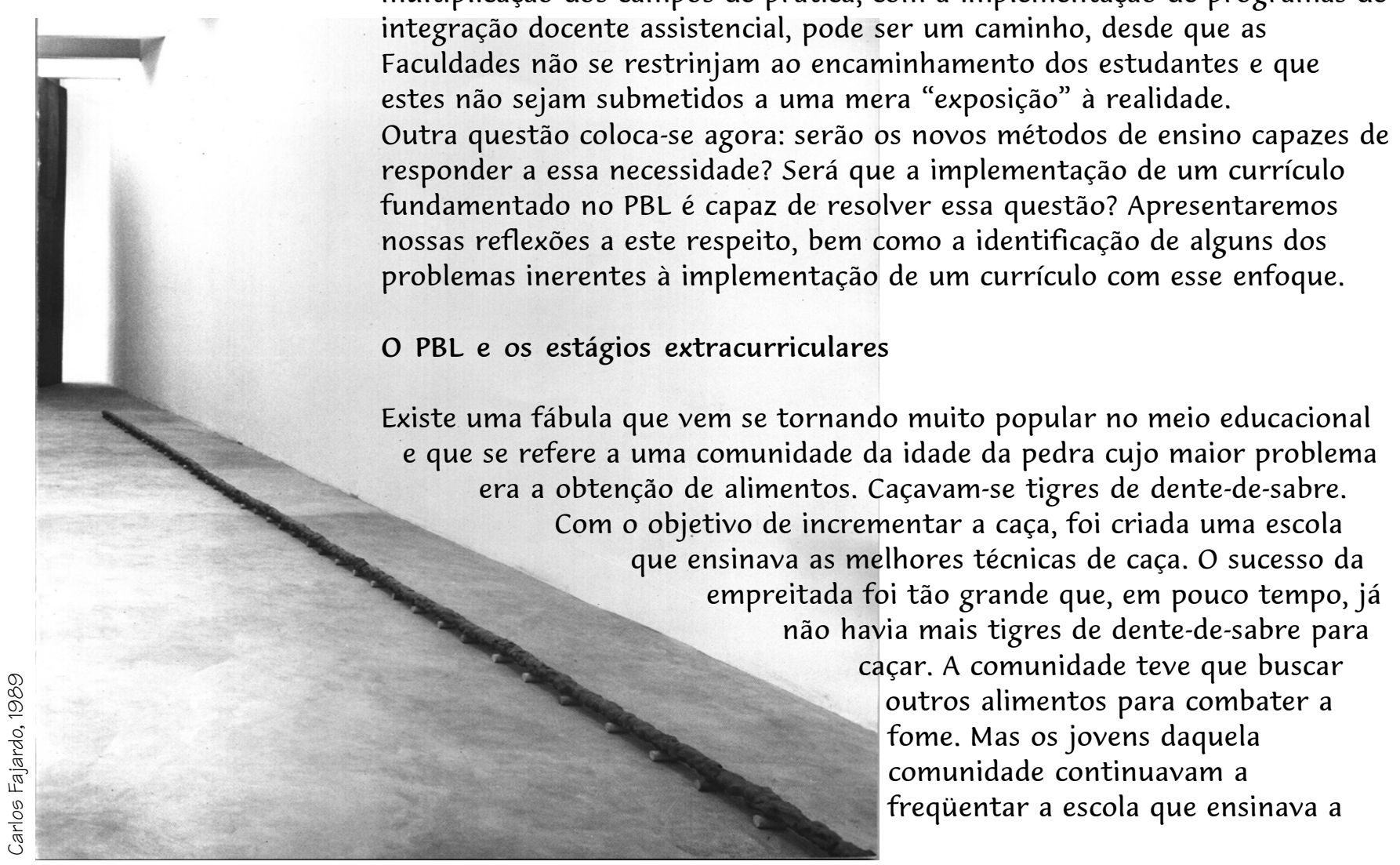

obter a história clínica do paciente costuma lhes ser atribuída. Os internos e residentes têm precedência, na hierarquia funcional de um hospital universitário. Na realidade, será apenas quando começarem seu internato que os alunos estarão efetivamente envolvidos, com responsabilidades, na assistência do paciente.

A discussão sobre a necessidade de ampliar a carga horária e a participação dos estudantes nas atividades práticas não é recente, sendo possível identificar propostas nesse sentido ainda na década de cinqüenta. Mas não basta apenas modificar a carga horária. A mudança precisa ser qualitativa. Nos estágios extracurriculares, longe da supervisão docente, os estudantes desfrutam de uma autonomia inaceitável e incompatível com seu nível de formação. Desempenham atividades que envolvem diagnóstico e terapêutica para os quais ainda não receberam formação adequada. Mas, no cotidiano desses estágios, nos quais os casos se multiplicam parecendo repetir-se em uma infinita monotonia, os alunos repetem procedimentos e rotinas, reduzindo a prática médica a um perigoso tecnicismo. Considerando-se que a maioria desses estágios se dá sob o regime de plantão, perdem também as possibilidades de acompanhar a evolução da doença do paciente atendido; de saber se efetivamente o diagnóstico estava correto e a terapêutica instituída adequada, ou não. Esta é uma das razões pela qual os estágios extracurriculares não podem ser mais tolerados. É também uma motivação a mais para que as Escolas Médicas redefinam suas práticas, reorganizando-as de maneira a envolver efetivamente seus alunos nas atividades clínicas, embora com responsabilidades compatíveis com sua formação. A multiplicação dos campos de prática, com a implementação de programas de integração docente assistencial, pode ser um caminho, desde que as Faculdades não se restrinjam ao encaminhamento dos estudantes e que estes não sejam submetidos a uma mera "exposição" à realidade.

Outra questão coloca-se agora: serão os novos métodos de ensino capazes de responder a essa necessidade? Será que a implementação de um currículo fundamentado no PBL é capaz de resolver essa questão? Apresentaremos nossas reflexões a este respeito, bem como a identificação de alguns dos problemas inerentes à implementação de um currículo com esse enfoque.

\section{O PBL e os estágios extracurriculares}

Existe uma fábula que vem se tornando muito popular no meio educacional era a obtenção de alimentos. Caçavam-se tigres de dente-de-sabre. Com o objetivo de incrementar a caça, foi criada uma escola que ensinava as melhores técnicas de caça. O sucesso da não havia mais tigres de dente-de-sabre para caçar. A comunidade teve que buscar outros alimentos para combater a fome. Mas os jovens daquela comunidade continuavam a freqüentar a escola que ensinava a 
${ }^{6}$ Alguns autores, como Berbel (1998), defendem uma terminologia diferente para o método quando utilizado em disciplinas isoladas ou apenas em alguns conteúdos específicos. Embora a distinção não seja essencial para a discussão aqui empreendida, é importante para aqueles que estejam envolvidos na implementação do novo método. caçar tigres de dente de sabre.

A reflexão que esta fábula proporciona é aplicável, sem grandes esforços, às discussões sobre o currículo médico. Como sabemos, o atual modelo hegemônico para o ensino da Medicina tem suas origens no distante relatório Flexner, nos idos de 1910. Embora façamos questão de nos diferenciarmos daqueles que se limitam a criticá-lo implacavelmente, sem reconhecer seus méritos, inclusive em uma perspectiva histórica, também o questionamos, já que nos parece que nos dias atuais estamos continuando a ensinar como caçar tigres de dente-de-sabre.

É nessa perspectiva que a metodologia do PBL parece-nos uma "inovação" especialmente alvissareira, inclusive no que se refere às questões sobre treinamento prático e desenvolvimento de habilidades específicas.

Acreditamos, entretanto, que exatamente pelas perspectivas vantajosas propostas pelo método, impõe-se sua apropriação cuidadosa, para não vê-lo como uma panacéia para os males que a educação médica tem apresentado. É sabido que desde as experiências pioneiras, há cerca de trinta anos, nas Universidades de McMaster, no Canadá e, posteriormente, na de Limburg, em Maastricht, na Holanda e em Newcastle, na Austrália, diversas outras Faculdades desenvolveram e implementaram currículos baseados no PBL. Já existe uma grande diversidade de experiências em curso, muitas se distanciando da "Meca" pioneira e mantendo programas simultâneos de currículos tradicionais com os baseados na nova metodologia, ou ainda implementando-a apenas em algumas disciplinas, especialmente naquelas do ainda chamado "ciclo básico"(Camp, 1996; Missouri, 1998 e Childs, 1997).6 Um currículo integralmente fundamentado no PBL oferece, ao menos teoricamente, mais vantagens para o processo ensino-aprendizagem do que aqueles estruturados segundo o modelo tradicional. Destacaríamos, em especial, aquelas decorrentes da relação pedagógica, cujo foco principal centra-se no aluno e não no docente, e o forte envolvimento com a realidade e o ambiente clínico que ele preconiza. Tais características são consonantes com a concepção de conhecimento como construção de relações significativas (construtivismo), cujo êxito na educação de adultos tem sido comprovado nas mais diferentes situações e campos do conhecimento em que foi aplicada. Nessa abordagem, o conhecimento não é algo dado, absoluto, que o aluno recebe pronto e acabado, mas algo que precisa ser construído por eles a partir de sua interação com o ambiente (tendo como referência seu conhecimento prévio e entendimento pessoal do mundo). As experiências pedagógicas fundamentadas no construtivismo têm sido bem sucedidas tanto na educação fundamental de adultos como em cursos de pós-graduação. Sua aplicação na educação básica de crianças, embora largamente difundida, ainda é fruto de muita controvérsia, algumas das quais também se estendem ao uso do PBL nos cursos de graduação, como veremos mais adiante.

O PBL pode ser entendido também como um método que possibilita ao aluno a experiência de aprender fazendo. E este fazer não está apenas relacionado à pesquisa por informações que auxiliem na compreensão dos problemas apresentados nos grupos de estudo. Um fazer que se restrinja apenas ao desenvolvimento do hábito e da capacidade da pesquisa. Refere-se 
7 Para maiores informações sobre dificuldades na implementação do PBL ver, por exemplo: Albanese, M. \& Mitchell, S. (1993) Aspy, D.N., Aspy, C.B. E Quimby, P.M. (1993)e Vernon, D.T. \& Blake, R.L. (1993). também, e especialmente, ao envolvimento direto com a realidade e com o ambiente clínico.

Existem porém, alguns obstáculos e dificuldades nesse processo vastamente referidos na literatura. Faremos aqui uma pequena síntese, como um contraponto indispensável ao excesso de otimismo que muitas vezes acompanha as discussões sobre o PBL. Além das dificuldades inerentes a qualquer mudança curricular e que estão relacionadas à criação de um novo currículo e às disputas de poder entre docentes, outras referem-se especificamente ao novo método, que pressupõe transformações significativas no comportamento de estudantes e docentes. Para alunos, traz uma revolução em relação ao modelo de ensino-aprendizagem. Para docentes, que passam a necessitar de uma carga horária maior para ensinar o mesmo conteúdo, um dos maiores desafios é resistir à tendência tradicional de dar uma "aula" sobre o tema.

A princípio, a mudança de currículo implica também em novos custos. Como as discussões ocorrem em pequenos grupos, são necessários mais docentes para cumprir o mesmo conteúdo. Outra questão habitualmente referida deve-se à dificuldade em adaptar os docentes ao papel de facilitador, o que demanda treinamentos específicos e uma maior disponibilidade ${ }^{7}$. Uma das mais polêmicas advertências apontadas na literatura sobre o tema é a possibilidade de o aluno formado segundo essa metodologia vir a encontrar dificuldades na aprovação em concursos para Residência Médica ou obtenção de cargos no serviço público, já que o processo de formação exige mais tempo para a construção dos conteúdos. Esse questionamento merece ser levado em consideração pelas escolas que estão iniciando 
${ }^{8} \mathrm{~A}$ Internet oferece a possibilidade de discussões amplas sobre o método e o rápido acesso a informações sobre sua implementação em inúmeras Faculdades em todo o mundo. Para subscrever listas de discussão sobre o PBL, enviar mensagem

"subscribe seu nome", sem aspas, para listproc@

sparky.uthscsa.edu el ou para majordomo@ eng.monash.edu.au, sendo que esta última refere-se a um curso de engenharia. Para o contato com organizações que promovem o uso do PBL, enviar mensagem para: Australian Problem Based Learning Network (alpil@ cc.newcastle.edu.au) ou Network for ComunityOriented Schools in the Health Sciences (secretariat@ network.rulimburg.nl) programas experimentais nesse sentido, buscando, por meio de um levantamento sistematizado, maiores informações sobre o desempenho de alunos egressos de programas semelhantes.

Concluindo, podemos afirmar que, ao menos teoricamente, a implementação de currículos que utilizem a metodologia do PBL pode vir a suprir as necessidades dos estudantes em relação à aquisição de sua experiência clínica, na medida em que estimula a autonomia dos estudantes e busca situar o processo de ensino-aprendizagem em íntimo contato com a realidade. Os pequenos grupos, com um médico tutor, tendem a possibilitar uma maior participação dos estudantes, fazendo com que eles deixem sua tradicional posição de espectadores privilegiados de uma ação de saúde, tornando-os sujeitos do processo. Podemos, neste momento, nos reportar novamente às tendências apontadas no início deste artigo, quando falávamos da tendência atual de fusão dos mundos da educação e do trabalho, o fim da tradicional seqüência educação-trabalho. Assim, respondendo a nossa própria provocação no título deste artigo, concluímos afirmando que sim. A introdução da metodologia do PBL pode ser uma luz que venha a proporcionar aos estudantes uma formação que articule teoria e prática sob os auspícios das escolas médicas, embora a simples adoção do método, sem que as questões aqui discutidas sejam levadas em consideração, seja insuficiente para resolver a questão ${ }^{8}$.

\section{Referências bibliográficas}

ALBANESE, M. e MITCHELL, S. Problem-based learning: a review of the literature on its outcomes and implementation issues. Academic Medicine, v. 68, n.1, p. 52-81, 1993.

ASPY, D.N. et al. What doctors can teach teachers about problem-based learning? Educational Leadership, v. 50, n.7, p. 22-4, 1993.

BECKER, H. S. et al. Boys in white: student culture in a medical school. Chicago: University of Chicago Press, 1984.

BERBEL, N. "A problematização e a aprendizagem baseada em problemas: diferentes termos ou diferentes caminhos?" Interface- Comunic, Saúde, Educ, v.2, n.2, p.139-54, 1998.

CAMP, M. G. "Problem-Based Learning: A Paradigma Shift or a Passing Fad?". MEO, 1, p.2, 1996.

CHILDS, G. V. The use of PBL in the proposed new curriculum. 1997, available from Internet: http://cellbio.utmb.edu/curriculum/PBL.htm.

COE, R. M. Sociologia de la medicina. 3.ed, Alianza Universidad, Versión Española, 1984.

COMISSÃO DE ENSINO MÉDICO DO MEC Documento n.2, In: Documentos do ensino médico. 3.ed. Brasília: MEC, 1989.

CONSELHO FEDERAL DE EDUCAÇÃO Resolução n.8 de 8/10/69, In: Currículos mínimos dos cursos de graduação. 4.ed. Brasília: MEC, 1981. GALLI, A Argentina: transformación curricular. Educación Medica y Salud, v.23, n.4, p. 344-53, 1989. 
KOIFAMN, L. A crítica ao modelo biomédico na reformulação curricular do curso de Medicina da Universidade Federal Fluminense. Rio de Janeiro, 1996. Dissertação (Mestrado). Escola Nacional de Saúde Pública, Fiocruz, 1996.

MERTON, R. K. "Some preliminaries to a sociology of medical education appendix A "Socialization: a terminological note". In: MERTON, R. et al. The student-physician: introductory studies in the sociology of medical education. Cambridge, Massachussetts: Harvard University Press, 1957.

MILLER, G. E. Teaching and learning in medical school. Cambridge, Massachussetts: Harvard University Press, 1961.

MINISTÉRIO DA EDUCAÇÃO E CULTURA Programa de integração docenteassistencial. Brasília, 1981. (Série Cadernos de Ciências da Saúde, n.3).

UNIVERSITY OF MISSOURI, 1998, available from Internet: http://www.hsc.missouri.edu/cares/som/curl.html.

REGO, S.T.A. A prática na formação médica: o estágio extracurricular em questão. Rio de Janeiro, 1994. Dissertação (Mestrado). Instituto de Medicina Social, UERJ, 1994.

SANTOS, B. S. Pela mão de Alice: o social e o político na sociedade pósmoderna. São Paulo: Cortez, 1995.

SANTOS, J. O. Educação médica filosofia, valores e ensino. Salvador: Gráfica e Editora Arembepe, 1987.

VERNON, D.T. e BLAKE, R.L. Does problem-based learning work? A metaanalysis of evaluative research. Academic Medicine, v. 68, n.7, p. 550563, 1993.

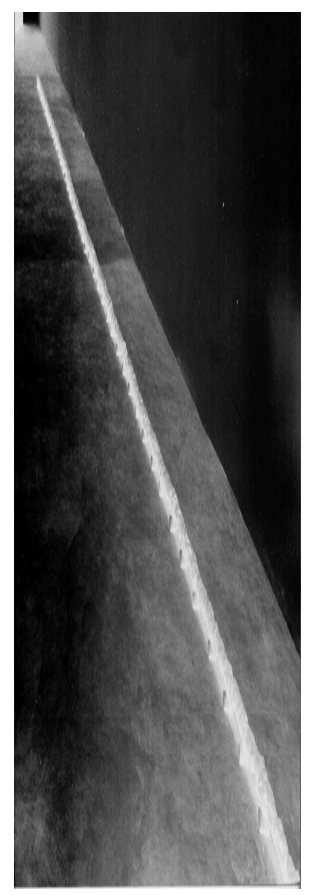

